\title{
Enzyme-linked immunosorbent assay using recombinant envelope protein 2 antigen for diagnosis of Chikungunya virus
}

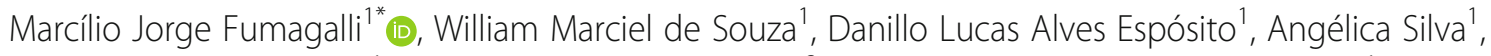
Marilia Farignoli Romeiro', Edson Zangiacomi Martinez², Benedito Antônio Lopes da Fonseca' and Luiz Tadeu Moraes Figueiredo ${ }^{1}$

\begin{abstract}
Background: Chikungunya (CHIKV) virus is an important mosquito-borne virus causing outbreaks of acute febrile illness with arthropathy. The detection of specific antibodies against CHIKV is used for diagnosis after the acute viremic phase of the disease. However, a major challenge for serologic diagnosis of $\mathrm{CHIKV}$ and other alphaviruses is the cross-reactivity of antibodies to common antigens among these viruses. In the present study, we have developed an enzyme-linked immunosorbend assay using a recombinant envelope protein 2 of CHIKV produced in Escherichia coli system, as a capture antigen.

Results: High titers (1600 to 12,800) of anti-CHIKV antibodies were detected in human sera analyzed by the CHIKV assay, suggesting it may detect low levels of the antibodies presence. On the other side, cross-reactivity was not observed in mouse hyperimmune sera to Mayaro virus and other alphaviruses analyzed by the CHIKV immunosorbend assay, suggesting it is a CHIKV-specific test. Fifty-nine human serum samples of CHIKV infection suspected cases were tested for immunoglobulin $\mathrm{G}(\mathrm{IgG})$ and $\mathrm{M}(\mathrm{IgM})$ antibodies detection using the CHIKV immunosorbend assay. A total of $44 \%$ (26/59) of samples were positive for lgG to CHIKV, determining $89.66 \%$ sensitivity and $100 \%$ specificity when the assay is compared to a CHIKV-specific neutralization assay. In addition, 40.6\% (24/59) of samples were positive for lgM, determining $92.48 \%$ sensitivity and $79.04 \%$ specificity by a Bayesian method in the absence of a gold standard. Moreover, CHIKV immunosorbend assay showed similar sensibilities to a commercial immunochromatography assay (Lumiquick, USA) for $\mathrm{CHIKV} \lg \mathrm{G}$ and lgM detection.
\end{abstract}

Conclusion: In short, we have developed a rapid, simple, specific and sensitive CHIKV immunosorbend assay for IgG and IgM detection and our results showed potential applicability on the diagnosis of infections by this virus.

Keywords: Chikungunya virus, Antibodies detection, Envelope protein 2, Serology

\section{Background}

Chikungunya virus (CHIKV) is included in the Semliki Forest group of the Alphavirus genus (Togaviridae family). CHIKV genome consists of a linear, positive-sense, single-stranded RNA of $\sim 11.8 \mathrm{~kb}$ in length including two open reading frames (ORFs) that encode four non-structural proteins (nsP1-4) and five structural proteins (C, E3, E2, $6 \mathrm{~K}$ and E1) [1]. CHIKV has been

\footnotetext{
*Correspondence: marcilio_jorge@hotmail.com; marcilio@usp.br

${ }^{1}$ Virology Research Center, Ribeirão Preto Medical School of University of São

Paulo, Ribeirão Preto, São Paulo, Brazil

Full list of author information is available at the end of the article
}

classified into three distinct lineages named as West African, Asian and East/Central/South African (ECSA) [2].

CHIKV is a mosquito-borne virus that causes human disease mainly characterized by acute onset fever and prominent arthropathy. Humans are infected by the bite of Aedes aegypti and Aedes albopictus [3]. CHIKV infection can cause persistent arthropathy for weeks to years, leading to incapacitation of patients and substantial economic loss [4].

CHIKV was first isolated from an acute febrile human case in 1953 during a Dengue epidemic in Liteho city, Tanzania [5]. CHIKV outbreaks were initially restricted

(c) The Author(s). 2018 Open Access This article is distributed under the terms of the Creative Commons Attribution 4.0 International License (http://creativecommons.org/licenses/by/4.0/), which permits unrestricted use, distribution, and 
to the African continent, and had several decades of relative inactivity, re-emerging in 2005 with significant outbreaks in Africa, Asia, Europe, and in islands of Indian and Pacific Oceans [6, 7]. In late 2013, CHIKV was reported in the Americas producing outbreaks in Caribbean islands [8]. Since then, local transmission has been described in many countries throughout the Americas [9]. In 2014, CHIKV was introduced twice in Brazil, one by the Asian strain in the North region and another by the ECSA strain in the Northeast region [10]. Only during 2016 and 2017, more than 460,000 suspected cases of CHIKV were reported in Brazil, leading to at least 383 deaths [11].

CHIKV is an important public health problem in the Americas requiring early and accurate diagnosis of infections for a proper health care of patients and adoption of adequate preventive procedures. Currently, CHIKV is diagnosed by using a Real time quantitative polymerase chain reaction (RT-qPCR). However, this assay allows detection only in early viremic phase, which typically lasts up to 6 days after disease onset [12]. The confirmation of CHIKV infection after viremic phase requires serological tests. Commercial and in-house serological methods have been reported, including those based on CHIKV native antigens [13] and those using recombinant antigenic proteins $[14,15]$. Most of these assays detect CHIKV specific and other alphavirus cross-reactive antibodies, evidencing low specificity. Additionally, the performance of commercially available rapid tests and the majority of Mac-ELISAs for antibody detection have shown low sensitivity $[16,17]$.

Herein, we show an ELISA using recombinant envelope protein 2 (rE2) of CHIKV as antigen. The rE2 of CHIKV expressed in Escherichia coli system was used in ELISA to detect IgG and IgM antibodies to CHIKV. To determine their sensitivities and specificities, results obtained with these assays were compared to those obtained with other routinely used serologic tests for diagnosis of infections by CHIKV.

\section{Results}

\section{Standardization of rE2-CHIKV ELISA}

A suitable amount of $44 \mathrm{kDa} \mathrm{rE2}$ of CHIKV was produced in E. coli cells, and its purity was confirmed by sodium dodecyl sulfate polyacrylamide gel electrophoresis (SDS-PAGE) and Western blot (Fig. 1a and b). The optimal concentration of recombinant $\mathrm{rE2}$-CHIKV for coating ELISA plate wells was determined based on a clear detection of anti-CHIKV antibodies using mouse hyperimmune serum, which was 10 times higher than the cut off. Higher concentrations of rE2 were not chosen because they did not increase the assay sensitivity. Thus, $1 \mu \mathrm{g} / \mathrm{ml}$ of $\mathrm{rE2}$-CHIKV per well after $18 \mathrm{~h}$ of coating incubation were chosen as suitable for the assay. Importantly, cross-reactivity of other mouse hyperimmune sera was not observed for alphaviruses, such as AURV,
EEEV, MAYV, MUCV, and WEEV in the rE2-CHIKV ELISA (Fig. 2).

\section{Evaluation of rE2-CHIKV ELISA}

Results obtained by rE2-CHIKV in IgG and IgM ELISAs analyzing 59 serum samples of CHIKV suspected cases were compared to those obtained using enzyme immunoassay with infected cultured cells (EIA-ICC), commercial immunochromatography assay and plaque reduction neutralization test of $50 \%$ of plaques $\left(\mathrm{PRNT}_{50}\right)$ (Table 1 and Additional file 1: Table S1). The IgG rE2-CHIKV ELISA showed a sensitivity of $89.66 \%$ and a specificity of $100 \%$ when compared to $\mathrm{PRNT}_{50}$ results, considering 80 as a titer cutoff. Importantly, all 26 positive results in rE2-CHIKV ELISA were also positive by $\mathrm{PRNT}_{50}$, and three false negative results were observed. The comparison of IgG CHIKV PRNT ${ }_{50}$ results with those obtained with CHIKV EIA-ICC and commercial CHIKV immunochromatography assay showed 82.76 and $89.66 \%$ sensitivity and 96.67 and $100 \%$ specificity, respectively (Table 2 ). Additionally, IgG positive serum samples in the rE2-CHIKV ELISA showed $73 \%$ of high, $8 \%$ of medium and $19 \%$ of low avidity (Additional file 1: Table S1). The Bayesian analysis estimated a sensitivity of $92.48 \%$ and specificity of $79.04 \%$ for the IgM rE2-CHIKV ELISA. Sensitivities and specificities for IgM detection of the EIA-ICC were 74.01 and 55.59\% and for the Commercial assay were 91.31 and $94.21 \%$, respectively (Table 3 ). In addition, IgM positive samples showed $25 \%$ of high, $29 \%$ of medium and $46 \%$ of low avidity (Additional file 2: Table S2).

\section{Discussion}

Techniques used for diagnosis of infections by CHIKV in the acute viremic phase include CHIKV isolation in cell culture, detection of viral antigens by enzyme immunoassay, immunofluorescence, and detection of the viral genome by RT-qPCR. However, these methods have reduced usefulness after the first week of disease [16, 18-20]. Alternatively, detection of specific antibodies against CHIKV is used for diagnosis after the acute phase. However, a major problem for serologic diagnosis of alphaviruses (including CHIKV) is the cross-reactivity of antibodies to common antigens of viruses of the genus [21, 22]. In the present study, we have used as ELISA antigen a recombinant E2 protein of CHIKV produced in E. coli. The production of recombinant antigen in $E$. coli allows the obtainment of high amounts of the viral product without contamination risk by viral handling. It is known that the E2 protein of alphaviruses is involved in binding and entry of the virus in host cells [23-25]. Besides that, E2 of $\mathrm{CHIKV}$ is an important viral antigen that induces neutralizing antibodies for host protection [26-28]. Hence, E2 protein contains suitable antigens for use in diagnostic 

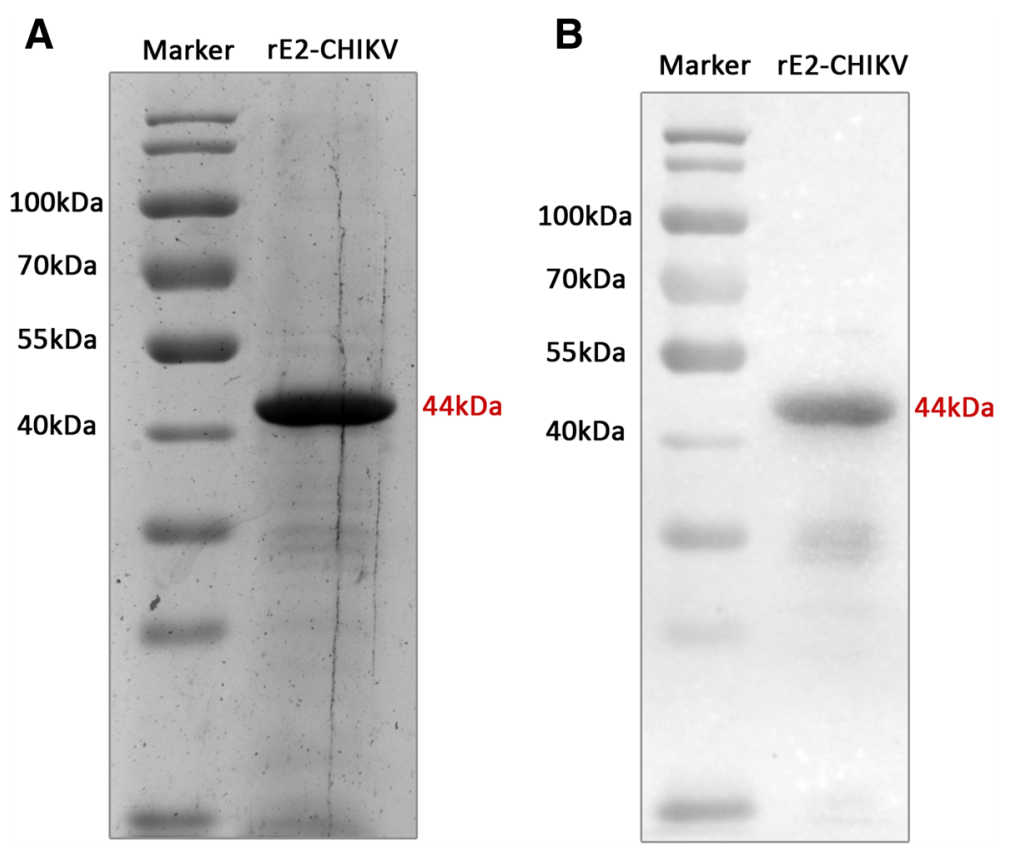

Fig. 1 Recombinant rE2-CHIKV antigen. a) SDS-PAGE showing the $\sim 44 \mathrm{kDa}$ band of rE2-CHIKV. b) Western blot using mouse monoclonal anti-his antibody conjugated to horseradish peroxidase (Sigma, USA)

serologic tests and also could be used as a potential vaccine candidate against CHIKV infection.

Testing human sera by rE2-CHIKV ELISA, we observed high antibody titer levels anti-CHIKV (1600 to 12,800), suggesting it may detect even low levels of anti-CHIKV antibodies present in the samples. On the other side, the rE2-CHIKV ELISA did not show any cross-reactivity signal with the polyclonal mouse hyperimmune serum anti-MAYV that is also a virus genetically grouped in the same Alphavirus Semliki Forest group of CHIKV [29]. The differential diagnosis of CHIKV cases with MAYV is important in Brazil and neighbor countries because both can produce a disease with similar symptoms [30].
Furthermore, cross-reactions to hyperimmune sera against other alphaviruses were not observed using the rE2-CHIKV ELISA, suggesting it is a CHIKV specific test that could overcome cross-reactions. These findings encourage the usage of rE2-CHIKV ELISA as a routine test for analysis of a high number of sera from patients with acute febrile illnesses discriminating those infected by CHIKV from infections by other arboviruses.

After the reemergence and spreading of CHIKV around the world, several assays have been developed to detect antigens and antibodies for CHIKV infection diagnosis [31]. Many of these serologic methods use viral antigens from cell culture and the virus in neutralization tests [32-35].

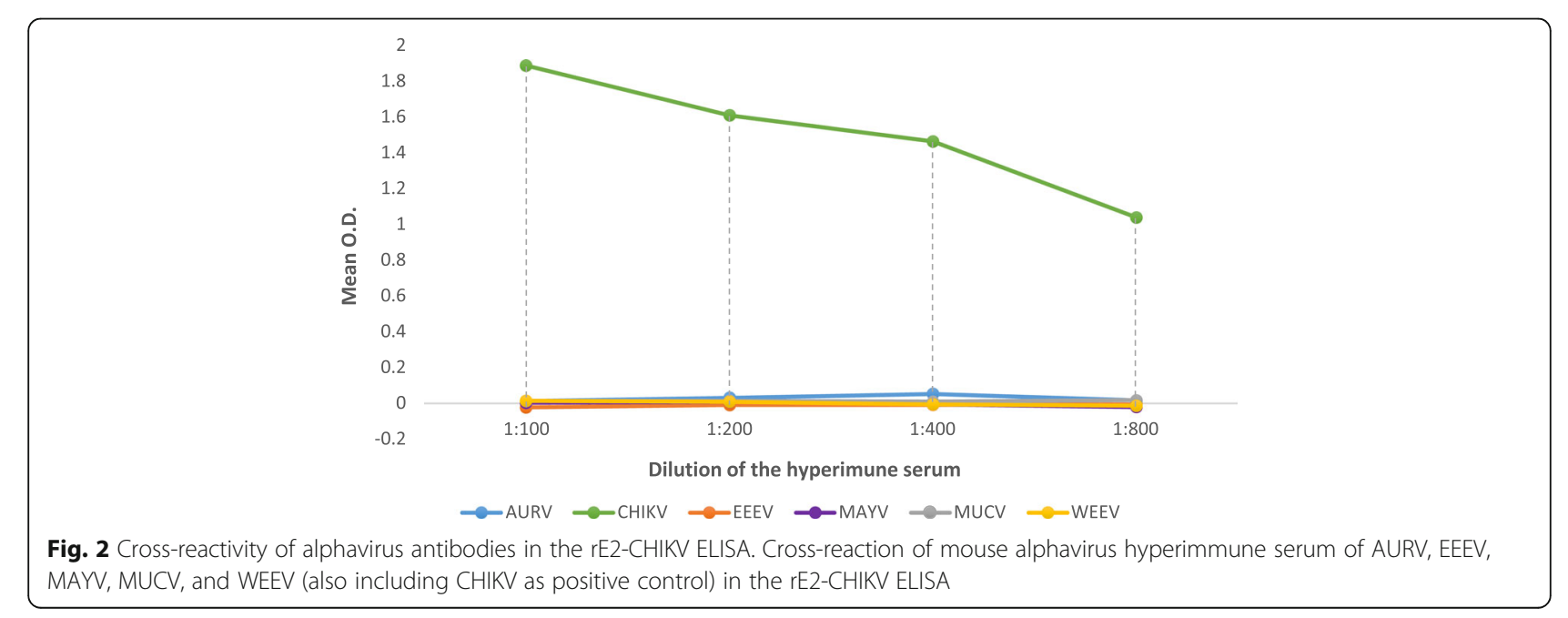


Table 1 Number of positive and negative samples detected by each of the assays

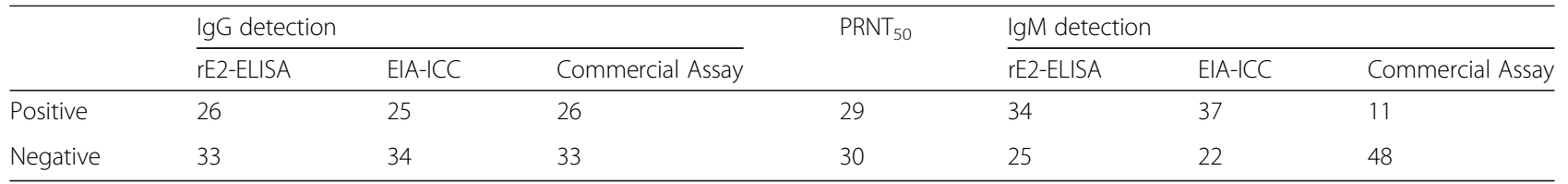

Fifty-nine human serum samples from CHIKV suspected cases were used to evaluate the performance of both IgG and IgM rE2-CHIKV ELISAs. The assay was able to detect $44 \%(26 / 59)$ IgG positive samples. These results, when compared to those obtained by $\mathrm{PRNT}_{50}$ for $\mathrm{CHIKV}$, a high specific assay, evidenced $89.66 \%$ sensitivity and $100 \%$ specificity for the IgG rE2-CHIKV ELISA. Moreover, the IgG rE2-CHIKV ELISA presented similar results to those obtained with two other enzyme immunoassays, the EIA-ICC and the commercial CHIKV immunochromatography assay (Lumiquick, USA), with 82.76 and $89.66 \%$ sensitivity and 96.67 and $100 \%$ specificity, respectively. A proportion of $73 \%$ of the IgG positive samples detected by rE2-CHIKV ELISA had high avidity to the rE2 protein, indicating a great affinity of these human serum antibodies to the antigen and corroborating the good efficiency of the assay. We highlight that IgG rE2-CHIKV ELISA described in the present study show several advantages compared to the other serologic assays that use native or recombinant viral antigens, like the EIA-ICC [36], total viral antigens [33], neutralization assay [35] and baculo-expressed proteins [14], which are more laborious and need biosafety specific care due to the handle of live viruses. Therefore, the IgG rE2-CHIKV ELISA could be recommended as a routine test for diagnosis of patients, particularly those with chronic arthropathy as well as for serologic surveys.

Evaluating the fifty-nine human sera by the IgM rE2-CHIKV ELISA, the assay detected 40.6\% (24/59) IgM positive samples, demonstrating a high sensitivity (92.48\%), superior to that of the EIA-ICC (74.01\%) and slightly higher than that of the commercial assay (91.31\%). Also, the rE2-CHIKV ELISA presented a high specificity (79.04\%), especially when compared to that of the EIA-ICC (55\%). However, only $25 \%$ of IgM positive sera to CHIKV showed high avidity to the rE2 protein, which could be related to the preferential

Table 2 Analysis the assays regarding lgG detection of human serum samples compared to $\mathrm{PRNT}_{50}$ for $\mathrm{CHIKV}$

\begin{tabular}{lllll}
\hline Assay & \multicolumn{4}{l}{ Results for IgG detection } \\
\cline { 2 - 5 } & $\begin{array}{l}\text { Positive } \\
\text { samples }\end{array}$ & $\begin{array}{l}\text { Negative } \\
\text { samples }\end{array}$ & Sensitivity (\%) & Specificity (\%) \\
\hline PRNT $_{50}$ & 29 & 30 & - & - \\
rE2-CHIKV & 26 & 33 & $89.66 \%$ & $100.00 \%$ \\
EIA-ICC & 25 & 34 & $82.76 \%$ & $96.67 \%$ \\
Commercial Assay & 26 & 33 & $89.66 \%$ & $100.00 \%$ \\
\hline
\end{tabular}

binding of IgM on epitopes surface of E1-E2 glycoproteins, rather than to the individual E2 [37] or to the relative immaturity of the first produced antibodies in the acute phase of the infection by CHIKV [38]. The IgM detection results of our assay are in agreement with other studies that used rE2-CHIKV for IgM detection $[15,39]$. Our results encourage the use of IgM rE2-CHIKV ELISA as a routine test for diagnosis of recent CHIKV infection.

\section{Conclusions}

We have developed a specific and sensitive IgG and IgM assay for CHIKV diagnosis (rE2-CHIKV ELISA). The assay is also rapid, simple, cost-effective and safe. Our results reveal the great potential of this assay for diagnosis of CHIKV infections, which can be used as a routine diagnosis assay of acute or convalescent suspect patients, as well for serologic surveys.

\section{Methods}

\section{Recombinant antigen}

The recombinant antigen sequence of $\mathrm{rE} 2$ of CHIKV (strain DRDE-06), comprising 1167 nucleotides (nt) in length, without the transmembrane region (Genbank accession number MG945127), was cloned into a pET-30a plasmid vector and expressed in E. coli system with a six-histidine tag at $\mathrm{N}$-terminal portion by Biomatik Corporation (USA). The rE2 was purified under native conditions and its molecular weight, integrity, and purity were assessed by SDS-PAGE and Western blot using mouse monoclonal anti-his antibody conjugated to horseradish peroxidase (Sigma, USA).

\section{CHIKV ELISA with recombinant antigen E2 protein (rE2- CHIKV ELISA)}

The rE2 of CHIKV was used as an antigen in an indirect ELISA for diagnosis of CHIKV infection. Concentrations of $\mathrm{rE2}$, from $0.5 \mu \mathrm{g} / \mathrm{ml}$ to $8 \mu \mathrm{g} / \mathrm{ml}$, diluted in $0.05 \mathrm{M}$ Carbonate-Bicarbonate buffer pH 9.6 (Sigma-Aldrich, USA) were added to wells of microplates (Corning, USA) and as negative control, Escherichia coli cells extract was diluted in same dilution and added to the other half of the plate. Plates were incubated for 18 and $36 \mathrm{~h}$ in a wet chamber at $4{ }^{\circ} \mathrm{C}$ and washed between each assay step with $150 \mu \mathrm{l}$ of PBS-T (Phosphate-buffered saline (PBS) with $0.05 \%(\mathrm{v} / \mathrm{v})$ Tween ${ }^{\circ}$ ). After washing three times, plates were blocked for $2 \mathrm{~h}$ at $37^{\circ} \mathrm{C}$ with $150 \mu \mathrm{l}$ of $10 \%(w / v)$ non-fat dry milk in 
Table 3 Prior distribution estimates and Bayesian posterior distribution estimates for $\lg \mathrm{M}$ sensitivities and specificities of the assays

\begin{tabular}{|c|c|c|c|c|c|c|}
\hline & \multicolumn{4}{|c|}{ Prior distribution estimate } & \multicolumn{2}{|c|}{ Posterior distribution estimate } \\
\hline & Mode & $U L^{a}$ & $\mathrm{LL}^{\mathrm{b}}$ & Beta & Median & $95 \% \mathrm{Pl}$ \\
\hline \multicolumn{7}{|l|}{ Sensitivity } \\
\hline rE2-CHIKV ELISA & 0.9285 & & 0.90 & $100,8.623$ & 0.9248 & $0.8671-0.9638$ \\
\hline EIA-ICC & 0.4260 & 0.75 & & $1.235,1.317$ & 0.7401 & $0.4345-0.9478$ \\
\hline Commercial Assay & 0.9231 & & 0.90 & $100,9.247$ & 0.9131 & $0.9131-0.9574$ \\
\hline \multicolumn{7}{|l|}{ Specificity } \\
\hline rE2-CHIKV ELISA & 0.9665 & & 0.90 & $26.541,1.885$ & 0.7904 & $0.6841-0.8793$ \\
\hline EIA-ICC & 0.9850 & & 0.90 & $18.876,1.272$ & 0.5559 & $0.4340-0.6740$ \\
\hline Commercial Assay & 0.9411 & & 0.90 & $55.179,4.391$ & 0.9421 & $0.8829-0.9788$ \\
\hline
\end{tabular}

UL (upper limit): value considered (with $95 \%$ confidence) to be the highest possible value for that parameter

bL (lower limit): value considered (with $95 \%$ confidence) to be the lowest possible value for that parameter

PBS-T (blocking solution) to reduce background. In sequence, plates were washed three times and for positive CHIKV IgG, $50 \mu \mathrm{l}$ of different dilutions (1:100 to 1:800) of a mouse hyperimmune anti CHIKV serum diluted in blocking solution was added to the positive and negative wells. Plates were incubated $1 \mathrm{~h}$ at $37^{\circ} \mathrm{C}$ and washed four times. After, it was added $50 \mu \mathrm{l}$ of a 1:2000 horseradish peroxidase (HRP)-conjugated to a goat immunoglobulin anti-mouse IgG ('Fab' specific, Sigma-Aldrich, USA) diluted in blocking solution. Plates were incubated $1 \mathrm{~h}$ at $37{ }^{\circ} \mathrm{C}$, washed five times and it was added $100 \mu \mathrm{l}$ of 2,2' -Azinobis [3-ethylbenzothiazoline-6-sulfonic acid]-diammonium salt (ABTS) peroxidase substrate (KPL, USA) per well and incubated for $15 \mathrm{~min}$ at $37^{\circ} \mathrm{C}$ for test revealing. The plates were read in Titertek Multiscan MMC/340 Microplate Reader at an optical density (O.D.) of $405 \mathrm{~nm}$. ELISA cutoff values were calculated as the mean O.D. of negative controls plus three standard deviations (SDs). All samples were tested in duplicate. Sample with an average O.D. above the cutoff value was considered as positive [40].

\section{Cross-reactivity in the rE2-CHIKV ELISA}

In order to evaluate cross-reactivity of antibodies to alphaviruses in the rE2-CHIKV ELISA, mouse hyperimmune sera to AURV strain BeAr10315, EEEV strain BEAN-1999, MAYV strain BeAr20290, MUCV strain BeAn-8 and WEEV strain SpAn14723 were tested at different dilutions (1:100 to 1:800). These hyperimmune sera had their reactivity previously confirmed by indirect immunofluorescence tests [41] against their reciprocal viruses infecting tissue culture cells, labelling for nuclei, cytoplasm and the virus (Additional file 3: Figure S1).

\section{Testing human samples with rE2-CHIKV ELISA}

A total of 59 serum samples from patients clinically suspected of CHIKV infection were tested by rE2-CHIKV ELISA. Human assays used the HRP-conjugated goat anti-human IgG 'Fab' specific (Sigma-Aldrich, USA) diluted at 1:2000 or the HRP-conjugated goat anti-human

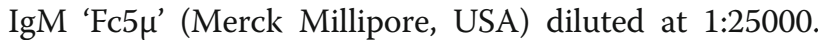
Positive samples were diluted from 1:100 to 1:25,600.

\section{Other serological tests used for diagnosis of infection by CHIKV}

Results obtained for the 59 human sera in IgG and IgM rE2-CHIKV ELISAs were compared to those obtained by an in-house EIA-ICC using C6/36 cells [42] and also to those obtained by a commercial immunochromatographic test for quick detection of anti-CHIKV IgG and IgM antibodies (Lumiquick, USA).

\section{Plaque reduction neutralization test}

To evaluate the specificity of anti-CHIKV antibodies in human serum samples, a $\mathrm{PRNT}_{50}$ was performed in Vero cells. Briefly, human sera previously inactivated were serially diluted (1/10 to $1 / 20,480)$ in Dulbecco's Modified Eagle's Medium (DMEM) (Vitrocell, Brazil). Subsequently, $1.75 \times$ $10^{2} \mathrm{PFU}$ of $\mathrm{CHIKV}$, strain BzH1, cordially provided by professor Benedito Antônio Lopes da Fonseca, were mixed with each serum and these mixtures were incubated for $1 \mathrm{~h}$ at $37^{\circ} \mathrm{C}$. Then, $200 \mu \mathrm{l}$ of each mixture was inoculated into Vero cell monolayers in 6 well plates. Cells were incubated $1 \mathrm{~h}$ at $37{ }^{\circ} \mathrm{C}$ under gently rocking. In sequence, $2 \mathrm{ml}$ of pre-warmed DMEM containing 1\% agar (Sigma, USA) and $3 \%$ fetal bovine serum (FBS) (Vitrocell, Brazil) were added to each cell monolayer well, and plates were incubated for 2 days at $37{ }^{\circ} \mathrm{C}$ at $5 \% \mathrm{CO}_{2}$ atmosphere. Finally, the cells were fixed in the wells with $4 \%$ formaldehyde (Labsynth, Brazil) solution for $2 \mathrm{~h}$ and stained with $1 \%$ crystal violet (Merck, USA) during $5 \mathrm{~min}$, for plaque visualization. Plaque reduction was calculated for each serum by comparing their respective number of plaques to the positive control, which was inoculated with $1.75 \times 10^{2}$ PFU of CHIKV. The cut off titer for positivity was set as 80 .

\section{rE2-CHIKV ELISA antibody avidity assay}

Human IgG and IgM positive samples in the rE2-CHIKV ELISA were submitted to an avidity assay [43]. Briefly, 
after primary antibody incubation, $100 \mu \mathrm{l}$ of a $6 \mathrm{M}$ urea solution diluted in PBS or only PBS was added to the wells, and the plates were incubated for $10 \mathrm{~min}$ at $37^{\circ} \mathrm{C}$ in a wet chamber. Then, plates were washed four times with PBS-T. The subsequent steps of the rE2-CHIKV ELISA were performed as described above. Relative avidity index (RAI) was calculated for each sample by dividing the liquid O.D. in urea treated wells by those in untreated wells (PBS), and proportions were showed in percentage. Samples with RAI $>60 \%$ were considered as having high avidity, 40 to $60 \%$ as medium avidity, and $<40 \%$ as low avidity.

\section{Bayesian analysis}

The sensitivity and specificity of rE2-CHIKV ELISA, EIA-ICC and immunochromatographic test for IgM detection were estimated by the Bayesian method introduced by Joseph et al. [44]. The Bayesian method allows us to estimate the accuracy of the test in the absence of a gold standard, by incorporating into the analysis prior knowledge about the performance measures. Prior information about test sensitivities and specificities was obtained from the literature $[13,15,36]$ and data available from LumiQuick Inc. (Santa Clara, USA), and it was represented by the use of beta $(\mathrm{a}, \mathrm{b})$ probability distributions, where the values of "a" and "b" determine the shape of the curve. These values were assessed using the function epi.betabuster of the epiR package in $\mathrm{R}$ software. This function calculates the values "a" and "b" based on a prior estimate and a $100(\mathrm{p}) \%$ uncertainty range, defined by a lower (LL) or upper limit (UL). Bayesian analyses were based on Markov chain Monte Carlo (MCMC) computations and performed with OpenBUGS (Imperial College and MRC, United Kingdom, available at www.mrc-bsu.cam.ac. $\mathrm{uk} /$ software/bugs). Posterior inferences were based on summaries of 1,000,000 iterations with a sampling lag of 10 , after a burn-in of 10,000 iterations. The final results were presented as a median and a $95 \%$ probability interval (PI, percentiles 2.5 and 97.5) of each parameter estimate.

\section{Additional files}

Additional file 1: Table S1. Detection results of human samples obtained by rE2-CHIKV ELISA, EIA-ICC, CHIKV commercial assay and PRNT $_{50}$. Bold or POS.: positive sample, ND: Not detected. (DOCX 18 kb)

Additional file 2: Table S2. The relative avidity index for $\lg G$ and $\lg M$ of each sample. Samples with RAI $>=60 \%$ were considered of High Avidity, between 40 and $60 \%$ of Medium Avidity and $=<40 \%$ of Low Avidity. ND: Not detected. (DOCX $15 \mathrm{~kb}$ )

Additional file 3: Figure S1. Immunofluorescence assay of infected cells. Specific homotypic antibodies detection by infected Vero cells to the respectively hyperimmune sera of alphaviruses. Green: hyperimmune sera labeling viruses; Blue: Nuclei, Red: Cytoplasm; Pos.: Positive infected cells and Neg.: Negative non-infected cells. (PDF 599 kb)

\section{Abbreviations}

AURV: Aura virus; CHIKV: Chikungunya virus; DMEM: Dulbecco's Modified Eagle's Medium; EEEV: Eastern equine encephalitis virus; EIA-ICC: Enzyme immunoassay using infected cultured cells; ELISA: Enzyme-linked immunosorbend assay; FBS: Fetal Bovine Serum; HRP: Horsedish peroxidase; IgG: Immunoglobulin G; IgM: Immunoglobulin M; kDa: kilodalton; MacELISA: IgM capture enzyme-linked immunosorbend assay; MAYV: Mayaro virus; MUCV: Mucambo virus; O.D.: Optical Density; ORF: Open reading frame; PBS: Phosphate-buffered saline; PBS-T: Phosphate-buffered saline with Tween; PFU: Plaque forming unit; $\mathrm{PRNT}_{50}$ : Plaque reduction neutralization test of $50 \%$ of plaques; RAI: Relative avidity index; rE2: recombinant envelope protein 2; RNA: Ribonucleic acid; RT-qPCR: Real time quantitative polymerase chain reaction; SDS-Page: Sodium dodecyl sulfate polyacrylamide gel electrophoresis; WEEV: Western equine encephalitis virus

\section{Funding}

This work was supported by the Fundação de Amparo à Pesquisa do Estado de São Paulo, Brazil (Grant N. 14/02438-6, and Scholarships Nº. 16/01414-1, 12/24150-9, 17/13981-0, 14/20851-8).

\section{Availability of data and materials}

The nucleotide sequence of the recombinant envelope protein 2 ( $\mathrm{rE} 2$ ) of CHIKV used in this work have been deposited in GenBank under accession number MG945127.

\section{Authors' contributions}

MJF was responsible for the conceptualization, development of the methodology, experiments performing, administration of this project and responsible for the original draft preparation. WMS was involved in the method investigation, in the conceptualization and in the review and edition of the original draft. DLAE was involved during the experiments development of the methodology. AS was involved during the experiments development of the methodology. MFR was involved during the experiments development of the methodology. EZM did the formal statistical analysis of this work. BALF was involved in the investigation of the method and provided the laboratory samples. LTMF was involved in the supervision and planning activity and methodology of this work. All authors read and approved the final manuscript.

\section{Ethics approval and consent to participate}

This study was approved by the Ethics Committee for Human Research of the School of Medical School of University of São Paulo, Ribeirão Preto, São Paulo, Brazil (No. 2.206.200).

\section{Consent for publication}

Not applicable.

\section{Competing interests}

The authors declare that they have no competing interests.

\section{Publisher's Note}

Springer Nature remains neutral with regard to jurisdictional claims in published maps and institutional affiliations.

\section{Author details}

${ }^{1}$ Virology Research Center, Ribeirão Preto Medical School of University of São Paulo, Ribeirão Preto, São Paulo, Brazil. ${ }^{2}$ Social Medicine, Ribeirão Preto Medical School of University of São Paulo, Ribeirao Preto, São Paulo, Brazil.

Received: 7 May 2018 Accepted: 17 July 2018

Published online: 24 July 2018

\section{References}

1. Burt FJ, Chen W, Miner JJ, Lenschow DJ, Merits A, Schnettler E, et al. Chikungunya virus: an update on the biology and pathogenesis of this emerging pathogen. Lancet Infect Dis. 2017;17(4):e107-17.

2. Volk SM, Chen R, Tsetsarkin KA, Adams AP, Garcia TI, Sall AA, et al. Genomescale phylogenetic analyses of chikungunya virus reveal independent emergences of recent epidemics and various evolutionary rates. J Virol. 2010;8413:6497-504. 
3. Diallo M, Thonnon J, Traore-Lamizana M, Fontenille D. Vectors of Chikungunya virus in Senegal: current data and transmission cycles. Am J Trop Med Hyg. 1999;602:281-6.

4. Schilte C, Staikowsky F, Couderc T, Madec Y, Carpentier F, Kassab S, et al. Chikungunya virus-associated long-term arthralgia: a 36-month prospective longitudinal study. PLoS Negl Trop Dis. 2013;73:e2137.

5. Ross RW. The Newala epidemic. III. The virus: isolation, pathogenic properties and relationship to the epidemic. J Hyg. 1956;542:177-91.

6. Schwartz O, Albert ML. Biology and pathogenesis of chikungunya virus. Nat Rev Microbiol. 2010;87:491-500

7. Mavalankar D, Shastri P, Raman P. Chikungunya epidemic in India: a major public-health disaster. Lancet Infect Dis. 2007;75:306-7.

8. Van Bortel W, Dorleans F, Rosine J, Blateau A, Rousset D, Matheus S, et al. Chikungunya outbreak in the Caribbean region, December 2013 to march 2014, and the significance for Europe. Euro Surveill. 2014;19:13.

9. Number of Reported cases of Chikungunya Fever in the Americas [Internet]. 2017. Available from: www.paho.org. Accessed 14 Mar 2018.

10. Nunes MR, Faria NR, de Vasconcelos JM, Golding N, Kraemer MU, de Oliveira $L F$, et al. Emergence and potential for spread of Chikungunya virus in Brazil. BMC Med. 2015;13:102.

11. SdVeSMd S. Monitoramento dos casos de dengue, febre de chikungunya e febre pelo vírus Zika até a Semana Epidemiológica 3, 2018. Boletim Epidemiológico. 2018;49(3):1-10. http://portalarquivos2.saude.gov.br/ images/pdf/2018/janeiro/30/2018-002.pdf

12. Lanciotti RS, Kosoy OL, Laven JJ, Panella AJ, Velez JO, Lambert AJ, et al. Chikungunya virus in US travelers returning from India, 2006. Emerg Infect Dis. 2007;135:764-7.

13. Khan M, Dhanwani R, Kumar JS, Rao PV, Parida M. Comparative evaluation of the diagnostic potential of recombinant envelope proteins and native cell culture purified viral antigens of Chikungunya virus. J Med Virol. 2014; 867:1169-75.

14. Kumar P, Pok KY, Tan LK, Angela C, Leo YS, Ng LC. Development and evaluation of baculovirus-expressed Chikungunya virus E1 envelope proteins for serodiagnosis of Chikungunya infection. J Virol Methods. 2014;206:67-75.

15. Cho B, Jeon BY, Kim J, Noh J, Kim J, Park M, et al. Expression and evaluation of Chikungunya virus E1 and E2 envelope proteins for serodiagnosis of Chikungunya virus infection. Yonsei Med J. 2008:495:828-35.

16. Johnson BW, Russell BJ, Goodman CH. Laboratory Diagnosis of Chikungunya Virus Infections and Commercial Sources for Diagnostic Assays. J Infect Dis. 2016;214(suppl 5):S471-S4.

17. Blacksell SD, Tanganuchitcharnchai A, Jarman RG, Gibbons RV, Paris DH, Bailey MS, et al. Poor diagnostic accuracy of commercial antibody-based assays for the diagnosis of acute Chikungunya infection. Clinical and vaccine immunology : CVI. 1810;2011:1773-5.

18. Godaert L, Najioullah F, Bousquet L, Malmontet T, Fournet B, Cesaire R, et al. Do two screening tools for Chikungunya virus infection that were developed among younger population work equally as well in patients aged over 65 years? PLoS Negl Trop Dis. 2017;111:e0005256.

19. Johnson BW, Goodman CH, Holloway K, de Salazar PM, Valadere AM, Drebot MA. Evaluation of commercially available Chikungunya virus immunoglobulin M detection assays. Am J Trop Med Hyg. 2016;951:182-92.

20. Okabayashi T, Sasaki T, Masrinoul P, Chantawat N, Yoksan S, Nitatpattana N, et al. Detection of chikungunya virus antigen by a novel rapid immunochromatographic test. J Clin Microbiol. 2015;532:382-8.

21. Thompson NN, Auguste AJ, Coombs D, Blitvich BJ, Carrington CV, da Rosa AP, et al. Serological evidence of flaviviruses and alphaviruses in livestock and wildlife in Trinidad. Vector borne and zoonotic diseases. 2012;1211:969-78.

22. Calisher CH, el-Kafrawi AO, Al-Deen Mahmud MI, Travassos da Rosa AP, Bartz CR, Brummer-Korvenkontio M, et al. Complex-specific immunoglobulin $M$ antibody patterns in humans infected with alphaviruses. J Clin Microbiol. 1986:231:155-9.

23. Bhatnagar S, Kumar P, Mohan T, Verma P, Parida MM, Hoti SL, et al. Evaluation of multiple antigenic peptides based on the Chikungunya E2 protein for improved serological diagnosis of infection. Viral Immunol. 2015;282:107-12.

24. Asnet Mary J, Paramasivan R, Tyagi BK, Surender M, Shenbagarathai R Identification of structural motifs in the E2 glycoprotein of Chikungunya involved in virus-host interaction. J Biomol Struct Dyn. 2013:3110:1077-85.

25. Weber C, Berberich E, von Rhein C, Henss L, Hildt E, Schnierle BS. Identification of functional determinants in the Chikungunya virus E2 protein. PLoS Negl Trop Dis. 2017;111:e0005318.
26. Smith SA, Silva LA, Fox JM, Flyak Al, Kose N, Sapparapu G, et al. Isolation and characterization of broad and Ultrapotent human monoclonal antibodies with therapeutic activity against Chikungunya virus. Cell Host Microbe. 2015;181:86-95.

27. Weber C, Buchner SM, Schnierle BS. A small antigenic determinant of the Chikungunya virus E2 protein is sufficient to induce neutralizing antibodies which are partially protective in mice. PLoS Negl Trop Dis. 2015;94:e0003684.

28. Warter L, Lee CY, Thiagarajan R, Grandadam M, Lebecque S, Lin RT, et al. Chikungunya virus envelope-specific human monoclonal antibodies with broad neutralization potency. J Immunol. 1865;2011:3258-64.

29. Powers AM, Brault AC, Shirako Y, Strauss EG, Kang W, Strauss JH, et al. Evolutionary relationships and systematics of the alphaviruses. J Virol. 2001;7521:10118-31.

30. Figueiredo LT. Emergent arboviruses in Brazil. Rev Soc Bras Med Trop. 2007:402:224-9.

31. Morrison TE. Reemergence of chikungunya virus. J Virol. 2014;8820:11644-7.

32. Kashyap RS, Morey SH, Ramteke SS, Chandak NH, Parida M, Deshpande PS, et al. Diagnosis of Chikungunya fever in an Indian population by an indirect enzyme-linked immunosorbent assay protocol based on an antigen detection assay: a prospective cohort study. Clinical and vaccine immunology : CVI. 2010;172:291-7.

33. Yap G, Pok KY, Lai YL, Hapuarachchi HC, Chow A, Leo YS, et al. Evaluation of Chikungunya diagnostic assays: differences in sensitivity of serology assays in two independent outbreaks. PLoS Negl Trop Dis. 2010;47:e753.

34. LaBeaud AD, Banda T, Brichard J, Muchiri EM, Mungai PL, Mutuku FM, et al. High rates of o'nyong nyong and Chikungunya virus transmission in coastal Kenya. PLoS Negl Trop Dis. 2015;92:e0003436.

35. Azami NA, Moi ML, Takasaki T. Neutralization assay for Chikungunya virus infection: plaque reduction neutralization test. Methods Mol Biol. 2016;1426: 273-82.

36. Figueiredo LT, Nogueira RM, Cavalcanti SM, Schatzmayr H, da Rosa AT Study of two different enzyme immunoassays for the detection of Mayaro virus antibodies. Memorias do Instituto Oswaldo Cruz. 1989:843:303-7.

37. Chua CL, Sam IC, Chiam CW, Chan YF. The neutralizing role of IgM during early Chikungunya virus infection. PLoS One. 2017:122:e0171989.

38. Victora GD, Nussenzweig MC. Germinal centers. Annu Rev Immunol. 2012;30:429-57.

39. Tripathi NK, Priya R, Shrivastava A. Production of recombinant Chikungunya virus envelope 2 protein in Escherichia coli. Appl Microbiol Biotechnol. 2014;986:2461-71.

40. Ramani S, Paul A, Saravanabavan A, Menon VK, Arumugam R, Sowmyanarayanan $\mathrm{TV}$, et al. Rotavirus antigenemia in Indian children with rotavirus gastroenteritis and asymptomatic infections. Clin Infect Dis. 2010;5111:1284-9.

41. Figueiredo LT. The use of Aedes albopictus C6/36 cells in the propagation and classification of arbovirus of the Togaviridae, Flaviviridae, Bunyaviridae and Rhabdoviridae families. Rev Soc Bras Med Trop. 1990;231:13-8.

42. Figueiredo LT, Shope RE. An enzyme immunoassay for dengue antibody using infected cultured mosquito cells as antigen. J Virol Methods. 1987:173-4. 191-8

43. Levett PN, Sonnenberg K, Sidaway F, Shead S, Niedrig M, Steinhagen K, et al. Use of immunoglobulin $\mathrm{G}$ avidity assays for differentiation of primary from previous infections with West Nile virus. J Clin Microbiol. 2005;4312: 5873-5.

44. Joseph L, Gyorkos TW, Coupal L. Bayesian estimation of disease prevalence and the parameters of diagnostic tests in the absence of a gold standard. Am J Epidemiol. 1995;1413:263-72.

\section{Ready to submit your research? Choose BMC and benefit from:}

- fast, convenient online submission

- thorough peer review by experienced researchers in your field

- rapid publication on acceptance

- support for research data, including large and complex data types

- gold Open Access which fosters wider collaboration and increased citations

- maximum visibility for your research: over $100 \mathrm{M}$ website views per year

At BMC, research is always in progress.

Learn more biomedcentral.com/submissions 